\title{
PIIISGUC.ORG
}

"iş, GÜÇ" ENDÜSTRI iLişKILERI VE INSAN KAYNAKLARI DERGISi

"IS, GUC" INDUSTRIAL RELATIONS AND HUMAN RESOURCES JOURNAL

\section{Hizmet İşletmelerinde İçsel Pazarlama Yaklaşımı}

\author{
Doç. Dr. Gökçe Özdemir \\ Yaşar Üniversitesi
}

Ocak/January 2014, Cilt/Vol: 16, Say1/Num: 1, Page: 54-66

ISSN: 1303-2860, DOI: 10.4026/1303-2860.2014.0246.x

Makalenin on-line kopyasına erişmek için / To reach the on-line copy of article:

http://www.isguc.org/?p=article\&id=541\&cilt=16\&sayi=1\&yil=2014

Makale İçin İletişim/Correspondence to:

Doç.Dr.Gökçe ÖZDEMIR / Email: gokce.ozdemir@yasar.edu.tr 


\title{
FIIISGUCOPG 0200020213 \\ "İş,Güç" Endüstri ilişkileri ve İnsan Kaynakları Dergisi "Işs,Güç" Industrial Relations and Human Resources Journal
}

\author{
Ocak/January 2014, Cilt/Vol: 16, Say1/Num: 1, \\ Sayfa/Page: 54-66, DOI: 10.4026/1303-2860.2014.0246.x
}

"İş,Güç" Endüstri İlişkileri ve İnsan Kaynakları Dergisi, yılda dört kez yayınlanan hakemli, bilimsel elektronik dergidir. Çalışma hayatına ilişkin makalelere yer verilen derginin temel amact; belirlenen alanda akademik gelişime ve paylaşıma katkıda bulunmaktır.

"İş,Güç" Endüstri İlişkileri ve İnsan Kaynakları Dergisi'nde, 'Türkçe' ve 'İngilizce' olarak iki dilde makale yayınlanmaktadır. "İş,Güç" Endüstri İlişkileri ve İnsan Kaynakları Dergisi, ulusal ve uluslararası birçok indekste taranmaktadır. (Cabell's Directories, Ebsco Socindex, Index Islamicus, Index Copernicus International, Worldwide Political Science Abstracts, Sociological Abstract, Ulakbim Sosyal Bilimler Veritabanı, ASOS Index)

Editörler Kurulu / Editorial Board Aşkın Keser (Uludă̆ University) K.Ahmet Sevimli (Uludă̆ University) Şenol Baştürk (Uludağ University)

\section{Editör / Editor in Chief}

Şenol Baştürk (Uludăg University)

\section{Uygulama / Design}

Yusuf Budak (Kocaeli University)

Tarandığı Indeksler / Indexes ASOS INDEX

CABELL'S DIRECTORIES EBSCO SOCINDEX Index ISLAMICUS Index COPERNICUS Int. Sociological Abstract ULAKBİM Sosyal Bilimler Veritanı

Worldwide Political Science Abstracts

\author{
Yayın Kurulu / Editorial Board \\ Dr.Şenol Baştürk (Uludă̆ University) \\ Yrd.Doç.Dr.Zerrin Fırat (Uludă̆ University) \\ Doç.Dr.Aşkın Keser (Uludă̆ University) \\ Prof.Dr.Ahmet Selamoğlu (Kocaeli University) \\ Yrd.Doç.Dr.Ahmet Sevimli (Uludağ University) \\ Doç.Dr.Abdulkadir Şenkal (Kocaeli University) \\ Doç.Dr.Gözde Yılmaz (Marmara University) \\ Yrd.Doç.Dr.Memet Zencirkıran (Uludă̆ University)
}

Uluslararası Danışma Kurulu / International Advisory Board

Prof.Dr.Ronald Burke (York University - Kanada)

Assoc.Prof.Dr.Glenn Dawes (James Cook University - Avustralya)

Prof.Dr.Jan Dul (Erasmus University - Hollanda)

Prof.Dr.Alev Efendioğlu (University of San Francisco - ABD)

Prof.Dr.Adrian Furnham (University College London - Ingiltere)

Prof.Dr.Alan Geare (University of Otago - Yeni Zellanda)

Assoc. Prof. Dr. Diana Lipinskiene (Kaunos University - Litvanya)

Prof.Dr.George Manning (Northern Kentucky University - ABD)

Prof.Dr.Mustafa Özbilgin (Brunel University - UK)

Assoc. Prof. Owen Stanley (James Cook University - Avustralya)

Prof.Dr.Işık Urla Zeytinoğlu (McMaster University - Kanada)

Ulusal Danışma Kurulu / National Advisory Board

Prof.Dr.Yusuf Alper (Uludă̆ University)

Prof.Dr.Veysel Bozkurt (Ístanbul University)

Prof.Dr.Toker Dereli (Işık University)

Prof.Dr.Nihat Erdoğmuş (İstanbul Şehir University)

Prof.Dr.Ahmet Makal (Ankara University)

Prof.Dr.Süleyman Özdemir (İstanbul University)

Prof.Dr.Ahmet Selamoğlu (Kocaeli University)

Prof.Dr.Nadir Suğur (Anadolu University)

Prof.Dr.Nursel Telman (Maltepe University)

Prof.Dr.Cavide Uyargil (Istanbul University)

Prof.Dr.Engin Yildırım (Anayasa Mahkemesi)

Doç.Dr.Arzu Wasti (Sabancı University)

Dergide yayınlanan yazılardaki görüşler ve bu konudaki sorumluluk yazarlarına aittir.

Yayınlanan eserlerde yer alan tüm içerik kaynak gösterilmeden kullanılamaz.

All the opinions written in articles are under responsibilities of the authors.

The published contents in the articles cannot be used without being cited. 


\title{
Hizmet İşletmelerinde İçsel Pazarlama Yaklaşımı
}

\author{
Doç. Dr. Gökçe Özdemir \\ Yaşar Üniversitesi
}

\begin{abstract}
Internal marketing application as a managerial approach is given attention and thus adapted by the service organizations. The power of interaction and relationship between the personnel and the customers affect the performance outcomes positively in service organizations. Therefore, companies value the development of a strong relationship with their personnel. Many research studies reveal that the effect of employee commitment, trust and satisfaction on high service quality and high customer satisfaction is mediated by internal marketing efforts. Investing in personnel is subject to bring success especially in the competitive market that differentiation of services is appreciated. Hence, the application of internal marketing in many service organizations is gradually expanded to such as banks, hospitals, airline companies, hotels and travel agencies. This study aims to enlighten and assess the internal marketing concept adopted by the service organizations to enhance the service quality and customer satisfaction based on internal communication and strong organizational culture.
\end{abstract}

Keywords: Internal Marketing, Internal Communication, Service Organizations

\section{Özet}

Içsel pazarlama uygulamalarl, özellikle hizmet işletmelerinin gün geçtikçe daha fazla önem verdiği ve uygulamaya koyduğu bir yaklaşım olarak dikkati çekmektedir. Hizmet işletmelerinde personel ve müşteri arasındaki ilişki ve iletişimin gücü işletmenin performans çıktılarını da olumlu yönde etkilediği için, işletmeler çalışanları ile olan ilişkilerini geliştirme çabalarına özen göstermektedir. Pek çok araştırma, içsel pazarlamanın işyerine bağglllğı, güveni ve memnuniyeti arttırdiğg dolaylstyla personelde yaratılan bu etkinin daha iyi bir hizmet sunumuna ve yüksek müşseri memnuniyetine aracllı ettiğini ortaya koymaktadır. Bu nedenle, rekabetin yoğun ve hizmetleri farklllaştırmanin zor olduğu günümüzde içsel pazarlama aracilğg ile personele yapılan yatırımların geri dönüşü başarı getirmektedir. İ̧sel pazarlamanın bankalar, hastaneler, havayolu işletmeleri, oteller ve seyahat acentaları gibi farkl hizmet alanlarındaki uygulamaları ise gittikçe yayginlaşmaktadır. Bu çalışma, hizmet işletmelerinde kalite artışına ve müşteri memnuniyetine neden olan içsel iletişimi ve güçlü bir örgüt kültürünü temel alan içsel pazarlama kavramına açılılı getirmek ve önemi üzerine değerlendirmeler yapmayı amaçlamaktadır.

Anahtar Kelimeler: Iç̧sel Pazarlama, İçsel İletişim, Hizmet İşletmeleri 


\section{Giriş}

İçsel pazarlama, bir hizmet işletmesinin müşteri ile doğrudan iletişimde olan ve destekleyici öneme sahip çalışanlarının müşteri memnuniyetini sağlamak üzere takım halinde çalışmaları için etkin bir şekilde eğitilmesi ve motive edilmesi anlamındadır (Kotler and Armstrong 2005: 260). Bu durumda içsel pazarlamanın amacı, aktif ve koordineli bir şekilde çeşitli faaliyetlerin örgüt içinde kullanıldığı pazarlama benzeri bir yaklaşımla, çalışanları hizmet anlayışı ve müşteri odaklı performansa doğru yöneltmektir (Varey 2001:195). Forsyth (2004:16)'in özellikle üzerinde durduğu gibi pazarlama başarısı ancak hem içsel hem de dışsal pazarlamanın etkili olması ve birinin diğerini desteklediği ve geliştirdiği durumlarda maksimize olmaktadır. $\mathrm{Bu}$ doğrultuda içsel pazarlama programı, dışsal pazarlama programı ile birlikte yürütülmeli; içsel plan dışsal planın aynası niteliğinde olmalıdır (Adcock, vd. 1995:354). İçsel pazarlama, örgüt bağlılı̆̆ı aracilığıyla işletmenin hedefleri doğrultusunda dışsal müşterilerin ihtiyaçlarını tatmin etme amacında bir örgütün tüm üyelerinin kendi rollerini ve iletişim becerilerini değerlendirmeleri ile müşteri bilinçliliği ve hizmet odaklılık anlayışını benimsemelerini sağlayan ve motive eden bir yönetim anlayışıdır (Varey 2001: 214-215).

Bir örgüt tarafından çalışanların işlerine içsel müşterilere sunulan ürün gözüyle bakmak, bu işlere hizmet yöneticilerinin mal ve hizmet tasarımına verdikleri önem kadar önem vermelerini gerektirmektedir (Lings, 2004:411). Çalışanlar da sahip oldukları işleri, zaman ile fiziksel ve ruhsal enerjilerinin karşılığında örgütler tarafından sunulan hizmetler olarak tecrübe etmektedirler (Podnar ve Golob, 2010: 1776). Doğan ve Kilıç'a göre (2008:26), çalışanlarına yani iç müşterilerine önem veren, onları güçlendiren, işletme içi iletişimin sürekliliğini sağlayan ve onları işletme hedefleri doğrultusunda motive eden işletmeler, dış müşterilerinin tatmini konusunda da başarılı olacaklardır. İçsel pazarlama iletişimi, çalışanların bir örgütün karşı karşıya kaldığı konuların önemini ve örgüt için kişisel olarak ne kadar önem taşıdıklarını anlamalarına yardımcı olur (Doukakis, 2002:99). İçsel iletişim örgütler için kritik bir fonksiyon olarak doğduğu için kendi içinde uzmanlı olarak düşünülmesi gerekmektedir (Tkalac et al. 2012:223).

Hizmetler, soyutluk, homojenlik, ayrılmazlık ve depolanamama gibi kendine özgü özelliklerle değerlendirmesi zor marka türlerini meydana getirir (Jevons, 2005:118). Bir mal satın alırken müşteriler ürün kalitesini değerlendirmek için stil, dayanıklılık, renk, etiket, paket, bedene uyma ve ürünün uyandırdığı his gibi pek çok somut ipucunu dikkate almakta ancak hizmet satın alırken fiziksel tesis, malzeme ve personel gibi daha az somut ipuçları dikkate alınmaktadır (Parasuraman et al., 1985:42). Etkili marka yönetimi için süreklilik önemli bir unsurdur ve çalışanların müşterilerle olan iletişiminde markanın temel değerleri yansitılabiliyor olmalıdır (King ve Grace, 2005:280). Ancak, hizmet işletmelerinde ön saflarda çalışan personelin pazarlama fonksiyonunun çoğunu yerine getirmesi, pazarlamanin sadece pazarlama ve satış departmanına bırakılmaması, tüm çalışanlar tarafından benimsenmesini gerektirmektedir (Kotler vd. 2006: 356). Çalışanların müşteri bilincinde olabilmesi, örgütün markasını destekleyen davranış ve hareketler sergilemesi ile mümkündür (King ve Grace, 2005:280). Bu anlamda içsel markalaşma, çalışanların uygun müşteri tecrübesi sunması için sürekli bir şekilde yetkilendirilmesi ve yönlendirilmesi ile ilgili stratejik süreçler setidir (Mude et al.2012:126). Müşterileri memnun etme doğrultusunda ön saflardaki çalışanları desteklemek ve onlara yardımcı olmak ise yönetimin ve destek personelinin görevidir (Frost ve Kumar, 2011:372).

Yüksek rekabet ve düşük çalışan morali için içsel pazarlamanın benimsenmesi bazı departman veya bireylerin diğerlerinden daha açık olması nedeniyle örgütün yürütülmesi 
üzerinde sinırlı bir etki yaratmaktadır (Kelemen \& Papasolomou-Doukakis, 2004:124). Bu anlamda içsel pazarlama, müşteriler ve çalışanlar arasındaki kişisel etkileşimi kolaylaştırarak dişsal ve stratejik pazarlama çalışmalarını tamamlamak üzere tasarlanmıştır (Varey 2001: 198). Nitekim, içsel ve dışsal ilişkiler kurmak örgütsel amaçlara başarıyla ulaşmak için birbirinden ayrılmaz iki önemli unsur olarak görülmektedir (Palmer, 1996:58). Şüphesiz hizmetlerin pazarlanmasında müşterilerle olan etkileşim süreci, uzun dönemli ilişkilerin geliştirilmesi ve böylece müşteri tutma ve uzun dönemli başarının sağlanması açısından çok önemlidir (Caruana ve Calleya, 1998:108). İçsel pazarlamanın başarısını engelleyen en önemli unsur ise işletmelerde uygulanan yıldırma çalışmalarıdır. Yıldırma sürecinin iç müşteri olarak nitelendirilen çalışanların tatminini olumsuz etkilemesi, sonuçta işletme başarısını önemli derecede azaltmaktadır (Çoban ve Nakip, 2007:309).

\section{1. İçsel Pazarlama Kavramı ve Yaklaşımı}

İçsel pazarlama kavramı ilk kez 1976 yılında Berry vd. tarafından incelenmiştir. İçsel pazarlama, pazarlama felsefesini ve uygulamasını dış müşteriye hizmet eden çalışanlara uygulayarak en iyi çalışanların işe alınması ve işte kalmalarının sağlanması anlamındadır (Greene vd. 1994:8). Ancak, pazarlama teknik ve kavramları içsel pazarlama alanina uygulaniyor olsa da pratikte nasıl uygulanacağı üzerinde dikkatle durulmalıdır (Rafiq and Ahmed, 1993:230). Bu anlayışa göre iç ve dış müşteriler hem yönetim hem de pazarlama kapsamında ayn önemde değerlendirilmelidir (Vrontis vd. 2010:38). İçsel pazarlama, çalışanları bir maliyet olarak görmekten ziyade onları işletmenin örgütsel başarısını sağlayacak ortaklar olarak gören bir kavramdır (Papasolomou, 2012: 111). İçsel pazarlama, içsel iletişimi ve müşteri bilinçliliğini iyileştirmeyi amaçlarken bu amaca içsel müşterilerin tatmini ile ulaşabilmektedir (Ballantyne, 1997:346). İçsel pazarlama mevut yeterlilikleri planlanmış stratejilere bağlayarak, planları gerçekleştirmek için yeterlilikteki boşlukları belirler (Ahmed ve Rafiq, 2003:1185). Ancak, içsel pazarlamanın etkili olabilmesi için, işletmenin fikirlerini müşterilerine satmadan önce çalışanlarına satması gerekir (Greene vd., 1994: 9). Bu anlamda bir örgütün içsel pazarı olan çalışanlar dış müşterilerin ihtiyaç ve beklentilerini karşılayabilmek için bilgilendirilmeli, eğitilmeli, yetiştirilmeli, ödüllendirilmeli ve motive edilmelidir (Doukakis ve Kitchen, 2004:421). Bununla birlikte içsel pazarlama zor anlaşılır bir kavramdır; hayalinde canlandırması kolay ancak gerçekleştirmesi son derece zordur (Ahmed ve Rafiq, 2003:1186).

Ulusal alanda yapılan çalışmalara baktığımızda içsel pazarlama araştırmalarının yazılı basın işletmeleri (Güneri ve Dündar, 2006), eğitim sektörü (Usta, 2009: 257; Demir

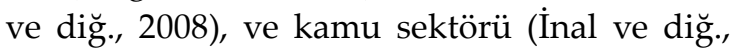
2008) gibi genel olarak hizmet sektörüne odaklandığı görülmektedir. Uluslararası çalışmalarda ise ağırlıklı olarak finans sektörü (Doukakis ve Kitchen, 2004; Caruana ve Calleya, 1998) ve turizm sektörü (Lin ve Lin, 2010; Frost ve Kumar, 2001; Vrontis vd. 2010) olmak üzere sosyal hizmetler (Cano ve Sams, 2009) gibi diğer hizmet alanlarında da içsel pazarlamaya yönelik çalışmaların yürütüldüğü görülmektedir. Candan ve Çekmecelioğlu (2009:56), örgütsel etkinlik ile ilişkili olduğu bulgulanan duygusal bağlılık ile normatif bağlılı̆̆ı arttırmak isteyen işletme yöneticilerinin çalışanlarını iç müşteri olarak gören içsel pazarlama faaliyetlerine önem vermeleri gerektiğini vurgulamaktadır. Ayrıca, Dabholkar ve Abston (2008:964) çalışmasında iç müşterilerin örgütün iç ve dış müşterisi olarak iki farklı rolleri olduğundan ve bunu içsel pazarlama ile desteklemenin öneminden bahsetmektedir. Bir işletmeyi etkili bir şekilde yönetmek, farklı fonksiyonel uzmanlıkların bütünleşmesini gerektirir ki yönetim sürekli ve karmaşık bir süreçtir (Varey ve Lewis, 1999:938).

\section{1. İçsel pazarlama ve dışsal pazarlama ilişkisi}

Bir şirketin mal veya hizmet ürünü pazarlamasından bağımsız olarak; dışsal pazarlama ve içsel pazarlamayı yerine 
getirerek etkili bir etkileşim pazarlaması yaratması, müşterilerle başarılı ve karlı uzun dönemli ilişkiler kurulmasına olanak vermektedir (Caruana ve Calleya, 1998:114). Pazarlama bakış açısı olmadan insan kaynakları yönetimi dışsal pazarlama programı ile bağlarını koparmış ve içsel rekabet avantajını da kaybetmiş olacaktır (Saad, 2002:47). Bu anlamda içsel pazarlama, çalışanların işletme yönetimi tarafından içsel pazar olarak değerlendirilmesini ifade etmektedir. Dışsal pazarın yanı sıra içsel pazar ile de sürekli iletişim halinde olmak içsel pazarlamanın gerekliliklerinden biridir. King ve Grace'in (2005:280) de belirttiği gibi etkili marka yönetimi için süreklilik önemli bir unsurdur ve çalışanların müşterilerle olan iletişiminde markanın temel değerleri yansıtılabiliyor olmalıdır. Örgütlerin markalarının çalışanlar tarafından içselleştirilmesi çalışanların pazar odaklı davranışları benimsemeleri ve sergilemelerini cesaretlendirmekle mümkündür (Azizi et al. 2012:127). Bu anlamda içsel iletişim bir markanın sürekliliğini sağlamak açısından önemli bir işlevi yerine getirmektedir. İşyerlerinde yeni medyanın özellikle intranetlerin kullanımının etkili içsel pazarlama iletişimi üzerinde olumlu bir etkisi olduğu gözlemlenmektedir (Bussy et al., 2003:156). Diğer yandan, internet iletişim teknolojileri tartışmasız çalışanları güçlendirirken işyerinin demokratikleşmesine de katkıda bulunur (Bussy et al., 2003:157). Böylece, içsel pazarlamanın gerektirdiği bu iletişim süreci, hem çalışanların örgüt içindeki rollerini anlamalarına yardımcı olur hem de bu rollerin örgütün çevresi ile olan ilişkilerindeki etkisini kavramasina neden olur (Hogg et al. 1998:893).

İçsel pazarlama, içsel kaynakları dışsal pazara uyumlaştırarak sinerjk bir avantaj elde etmek için gereçekleştirilen bir uygulamadır (Saad, 2002:47). Bansal vd. (2001: 65) dış müşteri memnuniyeti ve sadakati üzerinde etkili; işyeri güvenliği, yaygın eğitim, kısmen örgütsel performansa bağlı cömert ödüller, bilgi paylaşımı, yetkilendirme ve azaltılmış statü farkları olmak üzere altı adet içsel pazarlama uygulaması tanımlamıştır. Ayrıca pazar araştırma, bölümlendirme ve hedefleme gibi dışsal çevrede kullanılan kendini kanıtlamış araçlar da çalışanları motive etmek için de içsel olarak kullanılabilir (Saad, 2002:47). Nitekim Ene (2013:67) çalışmasında pazarlama kültürü oluşturulmasının işletmenin performansına, pazarlama etkinliğine ve pazarlama amacına olumlu katkıları olduğunu vurgular.

\section{2. İçsel pazarlama ve insan kaynakları ilişkisi}

Papasolomou (2003: 217), insan kaynakları yönetiminin içsel pazarlamanın ikamesi olarak görülmemesi gerekmekteğini savunmaktadır. İçsel pazarlama, müşteriye odaklandığı ve örgüt üyelerinin de nasıl müşteri odaklı olabileceği ve bu yüzden nasıl ödüllendirilebileceği üzerinde durduğu için, insan kaynakları yönetimin ötesinde bir uygulamadır (Papasolomou, 2003: 217). İçsel pazarlama gerçekten de insan kaynakları gelişimi, personel ilişkileri, stratejik yönetim, kalite yönetimi, örgüt içi iletişim ve makro pazarlama gibi pek çok farklı yönetim teknolojilerinin birleşimi niteliğindedir (Varey ve Lewis, 1999:938). Barnes et al. (2004:593) da Birleşik Krallık'ta orta ölçekli bir danışmanlık şirketinde yaptığ 1 araştırmaya dayanarak içsel pazarlama, ilişki pazarlaması ve hizmet kalitesi arasındaki bağ kapsamında bazı önerilerde bulunmuştur. Söz konusu öneriler müşteri odaklılık, iletişim, bilgi yönetimi, liderlik ve yönetim, iş tatmini ve personel devir hızı çerçevesinde geliştirilmiş ve bu önerilerin işletmenin başarılı geleceği için yol gösterici olması beklenmektedir. Chang ve Chang (2007:271) ile Ylddz (2011:223) ise araştırmalarında içsel pazarlamanın iş memnuniyeti ve örgütsel bağlllık üzerinde olumlu etkisi olduğunu destekler bulgulara ulaşmıştır. Bu doğrultuda, içsel pazarlama kapsamında insan kaynakları yönetim sistemlerinin tasarımı ve uygulanması çalışanların iş tatminini ile örgütsel bağlılığını arttıracak ve örgütsel hedeflere ulaşmak için çalışanları motive edecek bir etki yaratmaktadır (Tsai ve Wu, 2006:1295).

İş tatmininin artması çalışanların dış müşterilere hizmet ederken pozitif bir tutum sergilemelerine neden olacaktır ve böylelikle 
müşteri sadakati de artış gösterecektir (Tsai ve $\mathrm{Wu}, 2006: 1295)$. Gayretleri için sadece satış personelinin değil tüm destek personelinin de ödüllendirilmesi gerekir ve çalışanların başarısı için içsel pazarlamanın amaçları ve hedefleri doğrultusunda hem birincil hem ikincil ödüller verilmelidir (Papasolomou, 2003: 217). Çalışanların yaptıkları işten memnun olmalarını sağlama ve böylece daha yüksek kalitede hizmet sunmaları için motive etme amacında olan hizmet içi eğitim, içsel pazarlamanın en önemli unsurlarından biridir (Mosahab vd. 2011: 93). Tüketicilerin hizmetle ilgili beklentilerini oluşturma ve onları algılama sürecinde etkili hizmet kalitesini belirleyici olan özellikler: ulaşılabilirlik, iletişim, yeterlik, güvenirlilik, nezaket, güvenlik, kredibilite, heves, somut unsurlar ile müşteri tanıma ve anlama olarak ifade edilmektedir (Parasuraman et al., 1985:49). İçsel pazarlama hem çalışanların hem de müşterilerin ihtiyaçlarının tatmini ile bir işletme çalışanlarına görev bilincinin ötesinde iş yapmaları için ilham vererek önemli bir kuruluşun yaratılması ve sürdürülmesini sağlayabilir (Papasolomou, 2012:111). Çalışan memnuniyeti ise diğer içsel veya destekleyici birimler tarafından gerçekleştirilen hizmet kalite düzeyi tarafından belirlenmektedir (Kuei, 1999:785).

\section{3. İcsel pazarlama ve örgüt kültürü ilişkisi}

İçsel pazarlama programının başarılı olabilmesi için örgütün temel değerlerinin birbiriyle bağdaşıyor olması gerekir (Hogg et al. 1998:893). Güçlü ve bütünleşik bir kültüre sahip olmak etkili bir içsel pazarlama programının anahtarı iken ayn zamanda sonucu olarak da değerlendirilmektedir (Kelemen \& Papasolomou-Doukakis, 2004:125). Steyn vd. (2011: 139) çalı̧̧masında içsel pazarlamayı prensiplerini etkin bir şekilde uygulamak örgütsel kültürde "anlaşmazlıklar, bölünmeler ve kopukluk" ile sonuçlanabilecek zor bir süreç olarak tanimlamaktadır. Gounaris (2006:441), şirketlerin içsel pazarlamayı hayata geçirmemesinin nedeninin temel kültür yani içsel pazar oryantasyonu eksikliği olduğunu iddia etmektedir. $\mathrm{Bu}$ doğrultuda yapılan araştırmaya göre içsel pazar oryantasyonu içsel pazarlama çabalarını temel alan ve aynı zamanda söz konusu çabalar üzerinde doğrudan etkisi olan bir şirket felsefesi olarak tespit edilmiştir. Diğer bir deyişle, içsel pazarlama oryantasyonu, pazarlama yöneticilerinin insan kaynaklarını pazarlama planına katması ve insan kaynakları yöneticisinin ise pazarlama uygulamalarını insan kaynakları planına katmasını gerektirmektedir (Lings, 2004:411). İçsel müşteri oryantasyonu ve pazar oryantasyonunun gelişimi için işletme içindeki etkili iletişim çok önemlidir ve çalışanların pazar oryantasyonu üzerinde olumlu veya olumsuz etki yapan her fonksiyon içsel pazarlama çalışması olarak değerlendirilir (Conduit ve Mavondo, 2002:13).

Örgüt içinde güçlü içsel ilişki ağlarının oluşumu başarılı müşteri-örgüt ilişkilerinin kurulması için önemli bir şarttır (Bell et al. 2004:123). Kültürel uyum ve dayanışma örgütsel etkililiğe yol açarken, başarılı içsel pazarlama programının her zaman hizmet kalitesini ve müşteriye bağlılığı kavramış ve benimsemiş bir liderce başlatılması gerekir (Kelemen ve Papasolomou, 2007:750). İçsel pazarlamanın vizyon, ödül ve gelişim olmak üzere farklı bileşenleri vardır ve bu bileşenler içsel pazarlama amaçlarını gerçekleştirirken yöneticilerin göz önüne alması gereken önemli unsurlardir (Foreman ve Money, 1995:764). Nitekim, içsel pazarlamanın sadece pazarlama veya insan kaynakları uzmanlarının ilgi alanı olduğunu söylemek içsel pazarlama çalışanlarının ihtiyaçlarını dikkate almayan çok dar bir tanım olacaktır (Varey ve Lewis, 1999:938). Diğer yandan, içsel pazarlama uygulamalarının kültürel uyum sözü verirken gerçekte çalışanlar ile örgüt arasında çelişkili, muğlak ilişkilere yol açtığı görüşü tartışılmaktadır (Kelemen \& PapasolomouDoukakis, 2004:134).

\section{4. İcsel pazarlama ve toplam kalite yönetimi ilişkisi}

Toplam kalite yönetiminin yeniden konumlandırılması içsel pazarlama uygulamaları ile mümkündür ve bu doğrultuda hem iç hem dış müşterilerin 
ihtiyaç ve değerlerini anlamaya çalışmak, değer katan ve uygun stratejiler geliştirmek ve faaliyetlerin entegrasyon ve uyumunu sağlamak gerekmektedir (Longbottom et al. 2006:724). Yönetimin hedef aldığ konumlandirma ile sunulan hizmetin uyum içinde olması bir markanın başarısı için şarttır (King ve Grace, 2005:278). İçsel pazarlama faaliyetleri sadece çalışanların belirlenen hedefe ulaşmak için istekli olarak çalışmaları değil aynı zamanda müşteri problemleri ile yakından ilgilenmeleri ve içsel iletişimi geliştirme üzerine kurulmuştur (Finney ve Scherrebeck, 2010:327). Dolayısıyla, içsel pazarlama, istenilen hizmet kalitesini sunmak açısından örgüt sistem ve süreçlerini tamamlayan önemli bir uygulamadır (King ve Grace, 2005:287). Ayrica, küresel rekabet ortamında işletmelerin varlıklarını devam ettirebilmelerinin anahtarı olan toplam kalite yönetimi uygulamaları da içsel pazarlama yaklaşımından yararlanılmasını gerekmektedir (Çoban, 2004:95). Diğer yandan, toplam kalite yönetimine yönelik azalan ilgi dolayısıyla, uygulama hakkında devam eden şüphe ve tartışmalar söz konusudur (Longbottom et al. 2006: 709).

\section{5. İ̧sel pazarlama ve değişim yönetimi ilişkisi}

İçsel pazarlama, pek çok örgütün ihtiyaç duyduğu yeniden odaklanma için bir mekanizma görevi görür (Varey, 1995:48). İçsel pazarlama, çevresel değişimlere etkili bir duyarlılık, yeni tasarlanan yönetim düzenlemelerini benimsemede esneklik ve performansta sürekli bir iyileşme sağlayan bir süreç ve mekanizmadır (Varey, 1995:52). Değişim yönetimi ve seçilen pazarlara olan duyarlılık, pazarlama prensiplerinin tüm örgüt çapında uygulanmasını gerektirir (Varey, 1995:47). Ancak bazı zamanlarda çalışanların değişime yönelik direniş gösterdiği bilinmektedir. Bu anlamda, içsel pazarlamanın ana unsuru olan içsel iletişim, en temel tanımıyla tüm çalışanların örgütsel değer ve hedeflerinden haberdar olmasını sağlarken aynı zamanda çalışanları yeni politika ve felsefeleri kabul etme konusunda ikna edici bir rol oynamaktadır (Doukakis, 2002:88). Değişime direniş, değişimin değer verilen şeyler üzerinde yapacağı etkinin tahminine yönelik duygusal bir tepkidir (Vrontis vd. 2010:38) ve tüm çalışanlar içsel pazarlama aracılığıyla hizmet kalitesinin yaratılmasına yaptıkları katkıyı anladığı için, süreç değişimleri çalışanlar tarafından daha rahat kabul edilmektedir (Lings, 1999:474). İçsel pazarlamanın tam bir değişim yönetimi kavramı olarak sayılması için yeterince kanıt olmamakla birlikte, içsel pazarlamanın stratejik karar verme sürecinin gerektirdiği amaçlara ulaşmanın yarattığ 1 gerçek problemlerle başa çıkma aracı olarak kullanıldığına dair veriler bulunmaktadır (Varey, 1995:49).

\section{2. İçsel Pazarlama Uygulamaları}

İçsel pazarlama uygulamalarının özellikle hizmet işletmeleri için önemi büyüktür ve temelinde çalışanların ihtiyaçlarının tespiti ve bu ihtiyaçlarının karşılanması doğrultusunda çalışanların aidiyet duygusunun geliştirilmesi ve işletmeyi sahiplenmesi amaçlanmaktadır. Bu nedenle, pek çok hizmet işletmesi için içsel pazarlama uygulamasının ilk aşaması oryantasyondur. Oryantasyon, söz konusu işletmenin tüm politika ve prosedürlerinin yazılı metinler halinde ve ayrıca sözlü olarak çalışanlara aktarılması ve marka imajının çalışanlara benimsetilmesi sürecini kapsamaktadır. Diğer yandan, çalışanlara kişisel gelişimlerini sağlamak ve performanslarını geliştirmek için düzenlenen eğitimler, komforlu ve güvenli bir çalışma ortamının sağlanması, maaş dağılımının adil bir şekilde düzenlenmesi, ücretli ve ücretsiz izin hakları ile sigorta haklarından dürüst bir şekilde faydalandırılması, maddi veya manevi teşviklerin sağlanması, ayın elemanı seçimi, çalışanlara özel partiler, kutlamalar ve eğlenceli toplantıların düzenlenmesi gibi uygulamalar yine içsel pazarlama kapsamında motivasyon araci olarak değerlendirilmektedir. İçsel pazarlamanın temel unsurlarından biri olan işletme yönetimi ve çalışanlar arasındaki iletişim ise yazılı veya sözlü olarak sağlanmalıdır. $\mathrm{Bu}$ süreçte, seminerler, bültenler, aylık raporlar, işletme içinde kullanılan yazılım programları, internet ve e-postalar hizmet işletmeleri tarafından yoğun olarak kullanılmaktadır. 


\section{Sonuç}

Günümüzde içsel pazarlama daha çok hizmet pazarlaması odaklıdır ve hizmet pazarlaması da ürün odaklı geleneksel pazarlamaya katma değer sağlayan bir araç olarak kullanılmaktadır. Bu anlamda, pazarlamacilar şirket içerisinde çalışanlardan meydana gelen içsel bir pazarın varlı̆̆ının ve ihtiyaçlarının farkında olarak çeşitli pazarlama uygulamaları geliştirmeli ve benimsemelidir. Bu iç pazara yönelik programlar dişsal pazarlama faaliyetleri ile paralel ancak uyarlanmış bir içeriğe ve kapsama sahip olmalıdır. İçsel pazarlama faaliyetleri her zaman dişsal pazarlama faaliyetlerini destekleyen bir anlayış içermeli ve birbirlerini tamamlamalıdır. İçsel pazarlama, insan kaynaklarına yatırım yapılmasını gerektirmekte ve bu yatırımın yüksek performans ve yüksek müşteri memnuniyeti olarak geri dönmesini öngörmektedir. Nitekim, Papasolomou (2003: 218), içsel pazarlama uygulamalarına yönelik farkındalık ve anlayış artmadıkça, içsel pazarlamayı tüm yönetim sürecine adapte eden rakip işletemler ile başa çıkılamayacağını savunmaktadır.

İçsel pazarlama, daha çok hizmet işletmelerinin üzerinde durması gereken bir konu olarak dikkati çekmektedir. Nitekim hizmetler söz konusu olduğunda müşteri ve çalışanlar arasındaki etkileşim yüksek olmakta ve hizmet kalitesi de bu anlamda çalışanlar tarafından inşa edilmektedir. Bu nedenle içsel pazarlama, bir örgütü oluşturan tüm çalışanların iç pazar olarak dış müşteri odaklı çalışma motivasyonunu sağlayacak uygulamaları içerir. İç müşterilerin ihtiyaç, istek ve beklentilerinin karşılanması ancak doğru pazarlama prosedürlerinin hayata geçirilmesi ile mümkündür. Hizmetin standardizasyonu ve devamlılığı açısından iç müşteri olan çalışanların işgücü devir hızının düşük olması hizmet sektörü açısından özellikle önemlidir. Dolayısıyla işletmenin iç ve dış müşteriyi kaybetmeden çalışmalarını sürdürmesini sağlamak gerekir. Hizmetin en iyi şekilde yerine getirilerek iç ve $d_{1}$ ş müşterilerin ihtiyaçlarının giderilmesi amaçlanmaktadır. Her bir çalışana müşteri gözüyle bakılmalı ve pazar araştırması yoluyla her iki pazarın da ihtiyaç, istek ve beklentileri belirlenmelidir. Burada önemli olan ihtiyaçların doğru bir şekilde belirlenerek, iç ve dış pazarın tatminine yönelik uygun yol ve yöntemlerin saptanmasıdır.

İçsel pazarlama uygulayan örgütler, kazandığı rekabetçi avantaj sayesinde diğer örgütlerden bir adım öne geçmektedir. Bu anlamda örgütün çalışanlarını en değerli varlıkları olarak görmesi ve içsel müşteriler olarak değerlendirmesi içsel pazarlamanın ana konusunu oluşturmaktadır. İçsel müşterilerden oluşan içsel pazar kendine özgü uygulamalara ihtiyaç duymakta ve örgütsel hedeflere ulaşabilmek için çalışanların bilgilendirilmesi, eğitilmesi, yönlendirilmesi ve motive edilmesini içeren bir iletişim sürecini gerektirmektedir. Bu süreç ise farklı bireysel kültürlere sahip çalışanların ortak bir kültürde buluşmasını sağlayan çatı olarak tanımlanabilen örgüt kültürü güçlü olan hizmet işletmelerinde işlemektedir. İçsel pazarlama içsel iletişim kapsamında çalışanlara iletilmesi gereken bilgilerin belirlenmesi ve içsel iletişim ağları aracılığı ile bilginin paylaşılmasını gerekli kılmaktadır. Bilginin paylaşılması elektronik postalar, bültenler ve duyurular aracılığı ile olabileceği gibi yüz yüze iletişimle de gerçekleştirilmesi mümkündür. Özellikle gelişmekte olan ülkelerde bankalar gibi hizmet işletmelerinde, içsel pazarlamanın dış pazarı oluşturan işletmelere mükemmel hizmet sunmaya imkan veren iletişim akışı ve ciddiye alınması ve ödüller ile teşvikler göz önünde tutularak geliştirilmesi gereken bir konudur (Opoku, 2009:326).

İçsel iletişim aynı zamanda dış pazarlama faaliyetleri ile iç pazarın uyum içinde olmasına neden olurken, dış pazarlamanın başarısını güçlendirmekte ve daha kaliteli hizmet sunulmasına olanak tanımaktadır. Hizmet kalitesi akışı yönetimden çalışanlara ve çalışanlardan da müşterilere doğru gerçekleşerek bir ilerleme ve gelişim sağlanmış olacaktır. İçsel iletişim içsel pazarlamanın en önemli unsurudur. Bu anlamda çalışanlar ile yönetim ve yine çalışanlar arasındaki iletişim paylaşımı arttırarak örgüt kültürünün de yaratılmasına ve güçlenmesine neden 
olmaktadır. Böylece, karşılıklı taraflar birbirlerini daha iyi anlayacak, örgütün başarısındaki rollerinin farkında olacak ve sürdürülebilir bir örgüt kurulmasına aracılık edecektir. Müşteri bilinçliliği yaratmak, çalışanların örgüt markası kapsamında daha yaratıcı ve daha aktif olmalarını sağlayacak sinerjinin oluşmasını da mümkün kılacaktır. Örgütlerin markalarının çalışanlar tarafından içselleştirilmesi çalışanların pazar odaklı davranışları benimsemeleri ve sergilemelerini cesaretlendirmekle mümkündür (Azizi et al. 2012:127). Bu durumda içsel pazarlama etkili dışsal pazarlamanın bir önkoşulu olarak değerlendirilmeli ve örgütler tarafından gerekli önem verilerek uygulamaya konulmalıdır. İçsel pazarlama süreci iş tatmini yüksek olan iç pazarın, dış pazara yönelik hizmet performansina etki edecek ve müşterilerin de yaşadıkları deneyimden memnun olarak ayrılmalarına neden olacaktır.

\section{REFERANSLAR}

A., Parasuraman, Zeithamland, Valarie A.\& Berry,Leonard L. (1985), A Conceptual Model of Service Quality and Its Implications for Future Research Journal of Marketing, 49(4), 41-50

Aburoub, Abdelmoti Suleiman, Hersh, Abdullah Mohammad\& Aladwan, Kalil (2011), Relationship between Internal Marketing and Service Quality with Customers' Satisfaction, International Journal of Marketing Studies, 3(2), s. $114-115$

Adcock, Dennis, Bradfield, Ray, Halborg, Al \& Ross, Caroline (1995), Marketing: Principles \& Practice, Pitman Publishing, Great Britain, s. 354

Ahmed, P. K.\& Rafiq, M. (2003), “Internal Marketing Issues and Challenges", European Journal of Marketing, 37(9), 1177-1186, s. 11851186

Azizi, Shahriar , Ghytasivand, Fateme \& Fakharmanesh, Sina (2012), Impact of Brand Orientation, Internal Marketing and Job Satisfaction on the Internal Brand Equity: The Case of Iranian's Food and Pharmaceutical Companies, International Review of Management and Marketing 2(2), 122-129, s.127
Ballantyne, D. (1997), Internal Networks for Internal Marketing, Journal of Marketing Management, 13, 343-366, s. 346

Bansal, H. S., Mendelson, M.B.\& Sharma, B. (2001), "The Impact of Internal Marketing Activities on External Marketing Outcomes", Journal of Quality Management, 6, 61-76

Barnes, Bradley R., Fox, Martin T. \& Morris, D.S. (2004), Exploring the link age between internal marketing, relationship marketing and service quality: A case study of a consulting organization, Total Quality Management, 15(5/6), 593-601, s. 593

Bell, Simon J., Mengüc, Bülent \& Stefan, Sara L. (2004), “When Customers Disappoint: A Model of Relational Internal Marketing and Customer Complaints", Journal of the Academy of Marketing Science, 32(2), 112-126, s. 123

Berry, L.L., Hensel, J.S.\& Burke, M.C. (1976), Improving retailer capability for effective consumerism response, Journal of Retailing, 52(3), 3-14

Bussy, Nigel M. De, Ewing, Michael T.\& Pitt, Leyland F. (2003), Stakeholder the ory and internal marketing communications: a framework for analyzing the influence of new media, Journal of Marketing Communications, 9(3), 147-161, s. 156-157

Candan, Burcu\& Gündüz Çekmecelioğlu, Hülya (2009), İçsel Pazarlama Faaliyetlerinin Örgütsel Bağlılık Unsurları Açısından Değerlendirilmesi: Bir Araştırma, Yönetim 20(63), 41-58, s. 56

Cano, Cynthia Rodriguez \& Sams, Doreen (2009), The importance of an internal marketing orientation in social services, International Journal of Nonprofit and Voluntary Sector Marketing 14, 285-295

Caruana, A.\& Calleya, P. (1998), "The Effect of Internal Marketing on Organizational Commitment among Retail Bank Managers", International Journal of Bank Marketing, 16(3), 108-116, s. 114

Chang, C. S.\& Chang, H-H. (2007), "Effect of Marketing on Nurse Job Satisfaction and Organizational Commitment: Example of Medical Centers in Southern Taiwan," Journal of Nursing Research, 15(4), 265-274, s. 271 
Conduit, J.\& Mavondo, F.T. (2002), “How Critical Is Internal Customer Orientation to Market Orientation?", Journal of Business Research, 51, 11-24, s. 13

Çoban, Suzan \& Yıldırma, Mahir Nakip (2007), (Mobbing) Olgusunun İçsel Pazarlama İle İlişkisi: Nevşehir'de Bulunan Bankalar Örneği, İktisadi ve İdari Bilimler Dergisi,21(1), 307-320, s. 309-318

Çoban, Suzan (2004), Toplam Kalite Yönetimi Perspektifinde İçsel Pazarlama Anlayışı, Erciyes Üniversitesi İktisadi ve İdari Bilimler Fakültesi Dergisi, 22, 85-98, s. 95

Dabholkar, Pratibha A.\& Abston, Kristie A. (2008), The role of customer contact employees as external customers: A conceptual framework for marketing strategy and future research, Journal of Business Research 61, 959-967

Demir, Halis, Usta, Resul\& Tarhan, Okan (2008), İçsel Pazarlamanın Örgütsel Bağlılık ve İş Tatminine Etkisi, H.Ü. İktisadi ve İdari Bilimler Fakültesi Dergisi, 26(2), s. 135-161

Doğan, Selen \& Kılıç, Selçuk (2008), İlişki Yönetiminde İç ve Diş Müşteri Memnuniyetinin Sağlanması, KMU İIBF Dergisi, 10(14), 1-28, s. 26

Doukakis, I. P.\& Kitchen, P.J. (2004), “Internal Marketing in UK Banks: Conceptual Legitimacy or Window Dressing?", The Internal Journal of Bank Marketing, 22(6), 421-452, s. 421

Ene, Selda (2013), İçsel Pazarlamaya Yönelik Olarak Çalısanların Pazarlama Kültürünün Oluşturulmasının İşletme Performansını Arttırmadaki Rolü, International Journal of Economic and Administrative Studies, 5(10), 6791, s. 67

Finney, S.\& Scherrebeck, M.H. (2010), Internal marketing as a change management tool: A case study in re-branding, Journal of Marketing Communications, 16(5), 325-344

Foreman, S. K. \& Money, A. H. (1995), Internal Marketing: Concepts, Measurement and Application, Journal of Marketing Management,11, 755-768, s. 764

Forsyth, Patrick (2004), Marketing and Selling Professional Services: Practical Approaches to Practice Development, GBR: Kogan Page Limited, London, s. 16

Frost, F.\& Kumar, M. (2001), “Service Quality between Internal Customers and Internal
Suppliers in an International Airline", International of Quality Reliability Management, $18(4), 371-386$, s. 372

Gounaris, S. P. (2006), “Internal-Market Orientation and Its Measurement ", Journal of Business Research, 59, 432 - 448, s. 441

Greene, W. E., Wallsand, G.D.\& Schrest, L.J. (1994), "Internal Marketing: The Key to External Marketing Success", Journal of Services Marketing, 8(4), 5-13, s. 8-9

Güneri, Fırlar, Dündar, Belma \& Pelin, İ.(2006), "Içsel Pazarlama ve Toplam Kalite YönetimiTürkiye'deki Ulusal Basın İşletmelerinin Değerlendirilmesine Yönelik Bir Araştırma", Bilig, 37 , s. 131-153

Hogg, Gillian, Carter, Sara \& Dunne, Anne (1998), “Investing in People: Internal Marketing Corporate Culture", Journal of Marketing Management, 14, 879-895, s. 893

HuaKuei, Chu (1999), Internal service quality an empirical assessment, International Journal of Quality\& Reliability Management, 16(8), 783-791, s. 785

İNAL, Mehmet Emin, Akın, Murat\& Çiçek Recep (2008), “İçsel Pazarlama Anlayışı Bağlamında Kamu Sektörü Çalışanlarının Kurumsal Algilamalarının Değerlendirilmesi: Niğde Örneği", Mustafa Kemal Ünv. Sosyal Bilimler Enstitüsü Dergisi, 5(9), s. 161- 181

Jevons, Colin (2005), Beyond products brand management- Names, brands, branding: beyond the signs, symbols, products and services, Journal of Product \&Brand Management, 14(2), 117-118, s.118

Kang, G. D., James, J.\& Alexandris, K. (2002), Measurement of internal service quality: Application of the Servqual battery to Internal service quality, Managing Service Quality,12(5), 278-291

Kelemen, Mihaela\& Papasolomou, Ioanna (2007), Internal marketing: a qualitative study of culture change in the UK banking sector, Journal of Marketing Management, 23(7/8), 745-767, s. 750

Kelemen, Mihaela\& Papasolomou-Doukakis, Ioanna (2004), Can culture be changed? a study of internal marketing, The Service Industries Journal, 24(5), 121-135, s. 124-125-134 
King, C.\& Grace, D. (2005), Exploring the role of employees in the delivery of the brand: a case study approach, Qualitative Market Research, An International Journal, 8(3), 277-295, s. 278-280-287

Kotler, Philip \& Armstrong, Gary (2005), Principles of Marketing, Pearson Education International, New Jersey, s. 260

Kotler, Philip, Bowen, John T. \& Makens, James C. (2006), Marketing for Hospitality and Tourism, Pearson Education International, New Jersey, s. 356

Lin, C. F. \& Lin, Y. Y. (2010), Internal and External Marketing for Exotic Restaurants, Journal of Foodservice Business Research, 13, 193-216

Lings, Brooks, Ianand \& Roger, F.(1998), Implementing and measuring the effectiveness of internal marketing, Journal of Marketing Management, 14(4/5), 325-351, s. 28

Lings, I. N. (2004), “Internal Market Orientation: Construct and Consequences", Journal of Business Research, 57, 405-413

Lings, Ian (1999), Managing service quality with internal marketing schematics, Long Range Planning, 32(4), 452-463, s. 474

Longbottom, David, Osseo-AsareJr Augustus E., Chourides, Pieris \& Murphy, William D. (2006), Real quality: Does the future of TQM depend on internal marketing?, Total Quality Management \& Business Excellence, 17(6), 709-732

Mosahab, R. , Mahamad, O. \&Ramayah, T. (2011), Motivational Orientation as an Internal Marketing Tool in Service Training: A Study of Service Delivery in a Hospital, International Journal of Business and Management, 6(2), 93100, s. $93-96$

Mude, Girish, Undale, Swapnil \& Daigavhane, Vrushali (2012), Internal Branding As A Management Strategy: A Case Of Organized Retail Sector, International Journal Of Research In Commerce \& Management 3(6), 126-129, s.126

Opoku, Robert Ankomah, Atuobi-Yiadom, Nana , Chong, Cathryn Serwaah\& Abratt, Russell (2009), The impact of internal marketing on the perception of service quality in retail banking: A Ghanaian case, Journal of Financial Services Marketing,13(4), 317-329
Palmer, A. (1996), Linking external and internal relationship building in networks of public and private sector organizations: a case study, International Journal of Public Sector Management, 9(3), 51-60, s. 58

Papasolomou, I. D. (2003), Internal Marketing in the UK Retail Banking Sector: Rhetoricor Reality, Journal of Marketing Management, 19, 197-224, s. 217-218

Papasolomou, Ioanna, Kountouros, Haris \& Kitchen, Philip J. (2012), Developing a framework for successful symbiosis of corporate social responsibility, internal marketing and labor law in a European context, The Marketing Review, 12(2), 109-123, s. 111

Papasolomou-Doukakis, Ioanna2002), Internal Marketing: A Means For Creating A Sales Or Marketing Orientation? The Case Of Uk Retail Banks, Journal Of Marketing Communications 8, 87-100, s. 88-99

Podnar, K. \& Golob, U. (2010),Friendly flexible working practices within the internal marketing framework: a service perspective, The Service Industries Journal, 30(11), 1773-1786, s. 1776

Proctor, Tony (2000), Strategic Marketing: An Introduction, Routledge, London

Rafiq, M. \&Ahmed, P. K. (1993), The Scope of Internal Marketing: Defining the Boundary Between Marketing and Human Resource Management, Journal of Marketing Management, 9, 219-232, s. 230

Saad, N.M., Ahmed, P.K.\& Rafiq, M. (2002), Internal Marketing: Using Marketing-Like Approaches To Build Business Competencies And Improve Performance In Large Malaysian Corporations, Asian Academy of Management Journal, 7(2), 27-53, s. 47

Steyn, Elanie, Steyn, TFJ (Derik) \& Rooyen, Mariékevan (2011), Internal Communication at DaimlerChrysler South Africa: A Qualitative Perspective on Two-Way Symmetrical Communication and Internal Marketing, Journal of Marketing Development and Competitiveness, 5(4), 131-144, s. 139

Tkalac, Ana, Verci, Dejan \& Sriramesh, Krishnamurthy (2012), Internal communication: Definition, parameters, and the future, Public Relations Review, 38, 223-230, s. 223 
Tsai, Y.\& Wu, W.S. (2006), “Internal Marketing, Organizational Commitment and Service Quality", Service Systems and Service Management, 2006 International Conference on, 2, 1292-1298, s. 1295

Usta, Resul (2009), İçsel Pazarlama Ve Hizmet Kalitesi Arasındaki İlişki Üzerinde Örgütsel Bağlılık ve İş Tatminin Aracılık Etkisi, Erciyes Üniversitesi İktisadi ve İdari Bilimler Fakültesi Dergisi, 34, 241-263, s. 257

Varey, R. J. (1995), A Model of Internal Marketing for Building and Sustaining a Competitive Service Advantage, Journal of Marketing Management, 11, 41-54, s. 47-48-49-52

Varey, Richard (2001), Marketing Communication: An Introduction to
Contemporary Issues, Routledge, USA, 214-215, s. $195-198$

Varey, Richard J. \& Lewis, Barbara R. (1999), “A broad end conception of internal marketing", European Journal of Marketing, 33(9/10), 926-944, s. 938

Vrontis, D.,Thrassou, A.\& Zin, R. M. (2010), Internal marketing as an agent of change implementing a new human resource information system for Malaysian Airlines, Journal of General Management , 36(1), 21-41, s. 38

Yıldız, Süleyman Murat (2011), İçsel Pazarlama, İş Tatmini ve Örgütsel Bağlllık İlişkisi: Spor Okullarında Görev Yapan Antrenörler Üzerine Bir İnceleme, Selçuk Üniversitesi Beden Eğitimi ve Spor Bilim Dergisi, 13 (2), 216-225, s. 223 